\title{
VERBOS DE OBEDIENCIA EN SÓFOCLES. ESTUDIO SEMÁNTICO
}

The concept of obedience in this paper is understood as a valorative manifestation of politics. I try to define the moral quality of Man in the context of the polis. On the one hand, there are the verbs that indicate types of political behaviour of Man before the nomos; on the other hand, there are those that refer to a political behaviour developed within the boundaries of the genos. In the former, the idea of obedience corresponds to something completely political or of state level; in the latter, to political concepts such as morality or religion (family leval). Linguistically, the examination of the Sophoclean corpus is based on a detailed study of the context (linguistics and extralinguistics), where the main and most important factor correspond to the distribution of the classes and subclasses of words at sentence level.

\section{Concepto de obediencia y limites del campo}

Este estudio se basa en un concepto de obediencia como manifestación valorativa de lo político, referida a la calidad moral del hombre en cuento homo politicus. La esfera conceptual que se define aquí es la del comportamiento del hombre con su semejante, en el marco de la ley y en el espacio vital de la polis.

En la práctica de todo examen semántico es necesario distinguir un límite a partir del cual los significados del campo no serían ya funcionales o propiamente semánticos, sino asociativos. Aplicado a este caso concreto, el significado de obediencia es fácilmente relacionable con otros conceptos paralelos. Por ejemplo, el verso a $\rho \times \omega$ en voz pasiva significa 'recibir órdenes' o 'ser gobernado por': este sujeto que implica pasividad nos lleva a relacionar mecánicamente la idea de ser gobernado o mandado con la idea de ser obediente.

De la misma manera, verbos como $\sigma \varepsilon \beta \omega$, cuyo núcleo semántico indica respeto y piedad, pueden considerarse, en un primer momento, pertenecientes al campo semántico de la obediencia, y ello en virtud a 
la asociación entre la actitud piadosa o conducta sumisa y la idea de obediencia '.

Por otro lado, hay que descartar del campo de la obediencia un número considerable de verbos que, insertos en una estructuración contextual determinada a nivel de frase, pierden su funcionalidad política. Incluso si la idea de obediencia está implícita en el semantema del verbo, dichos verbos pierden su valor político, bien por estrecharse su significado a situaciones exclusivamente personales, sin repercusión en lo humano colectivo, bien por relegarse dicho significado a situaciones circunstanciales, carentes de proyección humana que refleje norma comunitaria de conducta moral ${ }^{2}$.

A este segundo caso de exclusión pertenecen ejemplos como el que cito a continuación, $O C 756$ :

\section{$\pi \varepsilon เ \sigma \theta \varepsilon i \varsigma$ $\varepsilon \mu o i$}

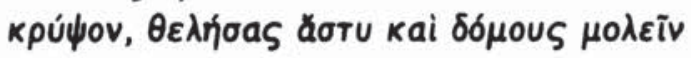

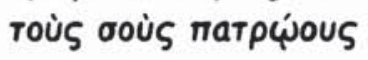

(Asi que tú, Edipo, por los dioses de tus padres), hazme caso y ocúltate, consintiendo en volver a tu ciudad y a tu hogar patrio.

[Creonte a Edipo ${ }^{3}$.

Se trata de una disputa particular, que no rebasa el ámbito de lo personal, y que sólo abarca el status de lo circunstancial, sin repercursión alguna en el de lo colectivo.

En otros casos, sin embargo, la interpretación del significado no está tan clara. Así por ejemplo, El. 308:

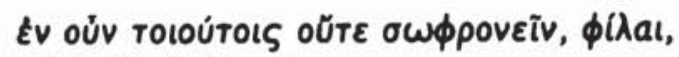

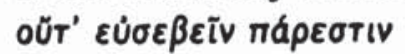

1 Ello no quiere decir que todos los usos de este verbo sean descartables por norma del campo semántico de la obediencia. Más adelante se verá que $\sigma \hat{\beta} \beta \omega$ posee funcionalidad política de obediencia en ciertos contextos. Aquí sólo pretendemos establecer unos principios que sirvan de orientación para marcar los límites del campo.

${ }_{2}$ Cf. A. Carmona Vázquez, El campo semántico de lo politico en Sófocles, Universidad de Cádiz, 1992 (cap. "Los límites del campo», pp. 76-86), donde hablamos de un tipo de conducta supraindividual, es decir, que rebasa la esfera de lo individual en el hombre, como la única capaz de originar y reflejar el concepto existencial de lo político para el hombre griego.

${ }^{3}$ En la traducción del griego hemos seguido las versiones de L. Gil (Sófocles: Antígona, Edipo Rey, Electra, Madrid 1960), A. Alamillo (Sófocles. Tragedias, Madrid 1981), F. Rodríguez Adrados (Sófocles. Edipo Rey, Madrid 1967) y J. M." Lucas de Dios (Sófocles. Ayax, Las Traquinias, Antígona, Edipo Rey, Madrid 1977). En otras ocasiones hemos traducido nuestra propia versión, ajustada a la interpretación personal del contexto, como es el caso de esta primera cita. Para el texto griego seguimos la edición de A. C. Pearson, Oxford 1975. 
En semejante situación, amigas, no es posible ser sensata ni piadosa [Electra al Coro].

Sólo podemos suponer que la idea de ser piadosa está haciendo referencia a una conducta de obediencia y recato. En casos como éstos decide el contexto $\mathrm{y}$, por qué no decirlo, la valoración personal del lector ${ }^{4}$.

\section{Usos de ámbito politico y usos de ámbito familiar-religioso}

No es la misma obediencia la que aparece en $T r$. 1251, oủ yàp ăv

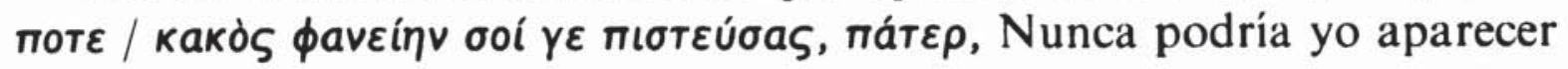
como un malvado por obedecerte, padre, [Hilo a su padre Heracles],

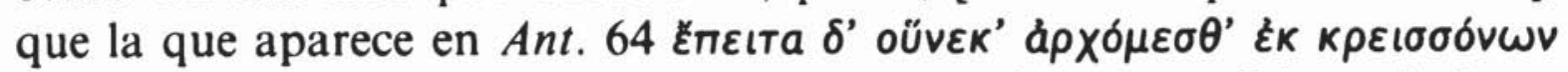

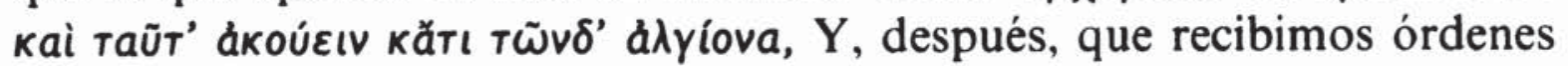
de quienes tienen mayor poder, de suerte que tenemos que acatar estas órdenes e incluso otras más penosas que éstas [Ismene a Antígona acerca del decreto del tirano].

De diferencias contextuales como éstas hemos constatado que los verbos de obediencia en Sófocles se refieren a dos tipos de conducta, diferentes por el ámbito en que se desarrolla cada una.

Por una parte, están los verbos que indican comportamiento del hombre ante el nomos, es decir, ante el espacio de lo estatal o propiamente político, que forman parte de un campo semántico figurado más amplio referido a la idea general de autoridad política ${ }^{5}$. El tema más frecuente en estos verbos es el de la violación o transgresión de la ley en el marco de la poli. Este primer grupo de verbos se relaciona con el ámbito de lo estrictamente político.

Por otra parte, están los verbos que se refieren al comportamiento moral del hombre en el espacio vital del genos, de la familia, en los que la idea de obediencia se hace expresión de un imperativo moral superior, basado mayormente en los lazos de sangre. El tema más frecuente en este segundo grupo es el de la piedad practicada entre los miembros

4 También son descartables del campo semántico de la obediencia las frases de tipo impersonal, en el sentido de presentar una ausencia real de sujeto como agente, promotor o implicado en los hechos. Se trata de frases en las que el sujeto suele ser un concepto de tipo abstracto, referido a lo ético, y en forma de infinitivo sustantivado. Los ejemplos son muy escasos.

5 El campo semántico de autoridad a que aquí nos referimos estaría formado, en principio, por significados como libertad, persuasión, poder, dominio, obediencia, servilismo, esclavitud, temor, etc., y sus contrarios. 
de dicha comunidad. De ahí que aparezcan tratados aquí argumentos como el de la obediencia debida al padre por parte del hijo, la fidelidad practicada entre amigos, o bien, la actitud piadosa ante los dioses. Este segundo grupo de verbos se relaciona con el ámbito familiar-religioso.

\section{Usos en el ámbito de lo político}

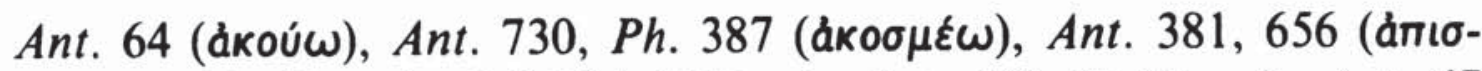

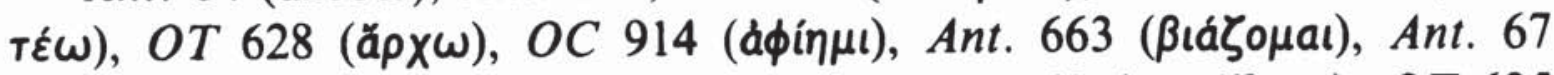

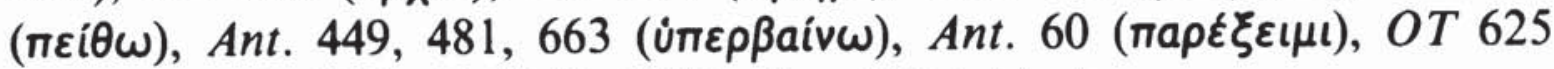

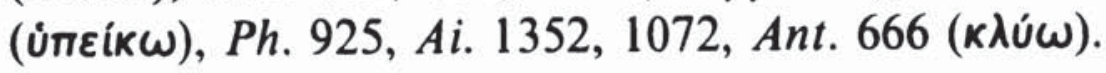

\section{Usos en el ámbito de lo familiar-religioso}

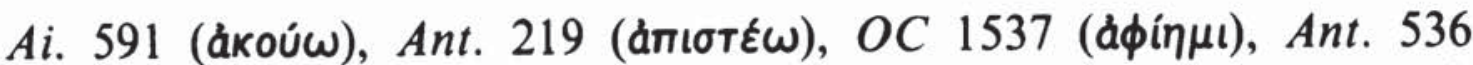

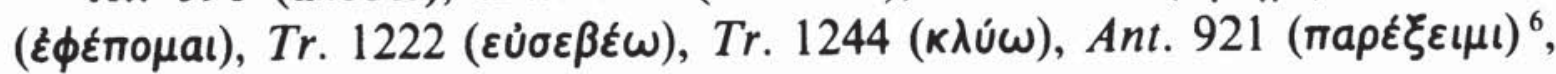
Tr. 1228, 1251 (пเбтยú).

\section{Distribución y subclases de palabras}

1) Sujeto de persona + Verbo transitivo + Complemento de tema-tipo, en acusativo referido al nomos:

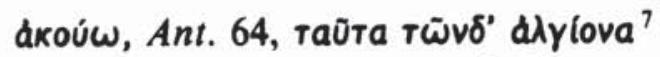

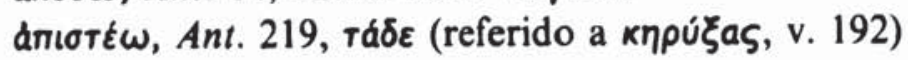

${ }^{6}$ El complemento del verbo es de tema-político: la ley divina formaba parte de lo estatal: por una parte, se puede considerar como verbo del primer grupo (uso en el ámbito de lo político), en cuanto que la impiedad hacia los dioses era objeto de sanción punible para el ciudadano; pero, por otra parte, se puede considerar como verbo del segundo grupo (uso en el ámbito de lo familiar-religioso), en cuanto se relegaba a la esfera familiar traduciéndose en un comportamiento virtuoso de la persona. Pensamos que aquí Antígona está apelando a su perspectiva íntima, vinculada a la esfera de lo familiar. Su código ético responde al resorte de las vóno ăypa$\phi o \iota . ~ S e ~ t r a t a$, por tanto, de un verbo del segundo grupo señalado. Para el tema de la impiedad como asunto estatal, cf. T. Calvo Martínez, De los sofistas a Platón, Madrid 1986, pp. 36-38.

7 Indicamos sólo el sintagma con función de complemento en acusativo del verbo correspondiente. Naturalmente, es necesario consultar el contexto próximo, es decir, los versos inmediatamente anteriores o posteriores al citado. Por otra parte, llamamos tem a-ti po a cualquier significado que, funcionando como complemento obligatorio del verbo, se refiera a una idea o entidad material reconocible como típica en el marco de lo político. Son te m a s- t i po por ejemplo, la obediencia al padre, el respeto o piedad ante los dioses, el cumplimiento o la transgresión de la ley, etc., $y$, en otros casos, la ley (como objeto de infracción), la Asamblea de los ciudadanos, el decreto del tirano, etc. 


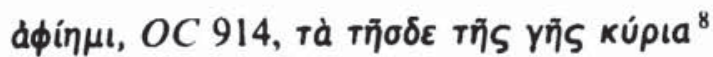
$O C, 1537$, тd $\theta \varepsilon i a^{9}$

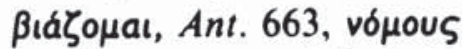

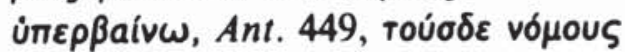

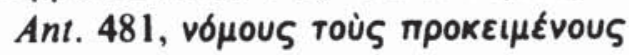

Ant. 663, vópous

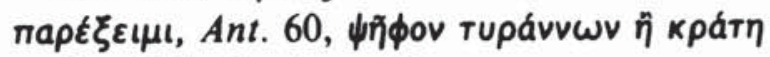

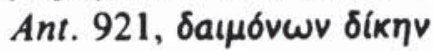

2) Sujeto de persona + Verbo intransitivo + Complemento de tema-tipo (en genitivo y dativo de persona-política ${ }^{10}$ ):

a) En Dativo:

dmı

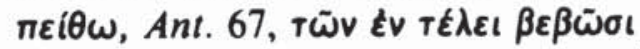

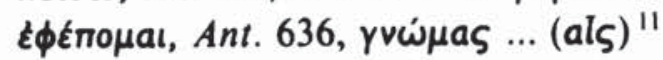

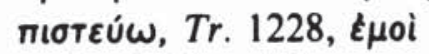

Tr. 1251, ool ${ }^{12}$

b) En Genitivo:

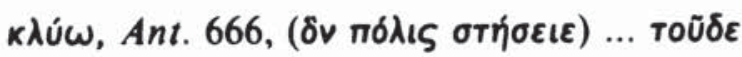

Ph. 925, Tüv $\varepsilon v T \varepsilon \lambda \varepsilon t$

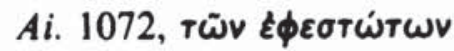

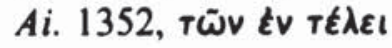

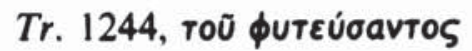

3) Sujeto de persona + Verbo intransitivo

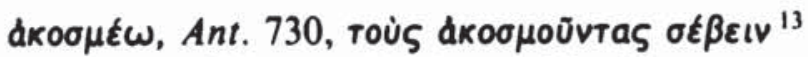

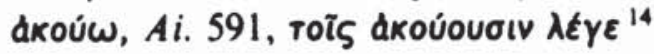

${ }^{8}$ El término kupía se refiere a la existencia en Atenas de un derecho que se tiene por sagrado, frente a la ciudad de Tebas, de la que procede Creonte. Este derecho está no solo en Atenas, sino en cualquier otra ciudad, y toda su circunscripción se tiene por inviolable. (Cf. K. Reinhardt, Sófocles, Barcelona 1991, pp. 284-286).

9 'Despreciando las normas divinas'. Con valor de tema político por el contexto en que está inserta la frase: cf. versos anteriores.

${ }_{10}$ La clase persona-politica se debe considerar también como tema-ti po, ya que, en última instancia, remite a la idea de gobierno, mando, poder, autoridad política.

"El tema es el de seguir los consejos del padre, obeceder al padre: no es el acu-

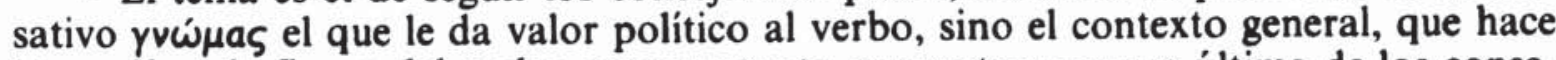
hincapié en la figura del padre, representante, promotor o causa última de los consejos al hijo. litica.

${ }_{12}$ Los dos complementos se refieren en el contexto a la clase de persona-po-

${ }_{13}$ En el caso de que el verbo funcione como intransitivo, citamos el sintagma donde aparece y, otras veces, la frase completa.

${ }_{14}$ En contra de la traducción más común, que suele interpretar el participio 


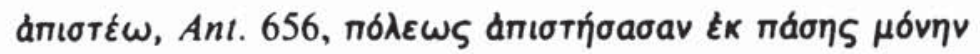

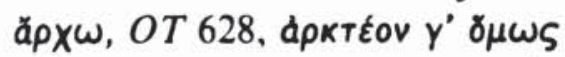

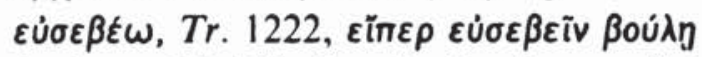

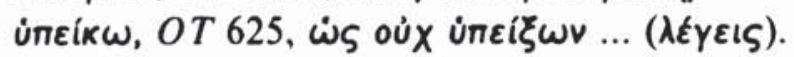

La distribución del significado verbal en la frase se apoya en los siguientes factores: 1) la actitud combinatoria del verbo ${ }^{15}$ (transitivos / intransitivos), y 2) un modelo estructural de oración formado por los tres componentes nucleares, sujeto, verbo y complemento. Las subclases de palabras en este primer nivel contextual son: Sujeto de persona (a veces es, además, de persona-política), verbo transitivo y verbo intransitivo, y complemento verbal de tema-político o personapolitica ${ }^{16}$. Por su parte, los restantes valores contextuales se reparten de manera desigual para cada verbo y según cada frase, dependiendo de condicionamientos mayormente conceptuales y extralingüísticos, que son los que deciden finalmente el significado del verbo en cada uso. Más adelante retomaremos el tema de los contextos en relación con cada uno de los verbos.

En el campo semántico de la obediencia las subclases de palabras corresponden sólo a conceptos típicos en el ámbito de lo político, en el sentido etimológico de la palabra. Se trata de los llamados te mas-ti pos o, en otros casos, pers on a-política. Por ello quedan excluidos del campo todos los demás casos que puedan referirse al ámbito de lo personal, es decir, todos los que indiquen circunstancias individuales, tal como hemos expuesto en los límites del campo.

Estos complementos de te ma-tipo son esencialmente de dos clases: 1) los pertenecientes al concepto de ley, relacionados con la cons-

como verbo de percepción sensorial ('escuchar'), proponemos para akoúw un valor contextual político, y traducimos 'a los que practican la piedad con los dioses', es decir, a los que aún tienen integridad moral, a los que aún no han perdido su honra, frente al mismo Ayax, que considera ya derrotado su honor.

15 Utilizamos el significado primario de actitud combinatoria, conforme lo considera Apresjan. Cf. "Analyse distributionnelle des significations et champs sémantiques structurées», Languages 1, 1966, pp. 44-74.

${ }^{16}$ De los múltiples valores que tiene el término distribución, la que aquí aplicamos es el gramatical: "La distribución gramatical o fundada en el orden de palabras puede darse en general en forma abreviada; indicación del caso regido o de la construcción, del carácter transitivo o intransitivo del verbo, de la clase de palabras del nombre sujeto, de la clase del verbo (accipiendi, de movimiento, de movimiento figurado, de «decir»), etc. Cf. F. Rodríguez Adrados, "Organización de los artículos del Diccionario. Criterios a seguir», en Introducción a la lexicografia griega, ed. por Elvira Gangutia, Madrid 1977, p. 261. Para este autor todos estos condicionantes son hechos de contexto: la distribución, que él llama "contexto sintáctico", es también un tipo de contexto. Para una delimitación de los conceptos de distribución y contexto, cf., en ese mismo artículo, el capítulo "Hechos distribucionales complementarios y hechos opositivos", pp. 271-273. 
trucción transitiva, y 2) los pertenecientes a la subclase de personapolitica, relacionados con la construcción intransitiva. En el primer caso, se trata del nomos (o un concepto equivalente) ${ }^{17}$, que suele aparecer como tal sustantivo en acusativo o bien en forma deíctica, referida al mismo concepto pero situado en versos anteriores. En el segundo caso, se trata de tipos como el Gobernante, el Padre, en relación al Ciudadano, al Hijo, respectivamente, etc., que aparecen en forma de sintagma sustantivado en genitivo o dativo ${ }^{18}$, o en forma de pronombre personal, también en los mismos casos gramaticales.

En líneas generales, los verbos de dos valencias (oraciones formadas por sujeto + verbo + complemento) son 1) verbos performativos que hacen referencia estrictamente al incumplimiento o violación de la ley, en cuanto acto que termina en la simple realización de sí mismo - en este caso el complemento es un acusativo de tema-tipo-, o 2) verbos referidos a la relación político-ética establecida entre dos personas-políticas - esta relación es comúnmente la de desobediencia en el caso de los verbos referidos a lo estrictamente político y la de piedad en el caso de los verbos referidos al ámbito familiar-religioso.

Si el verbo sólo posee una valencia (oración formada por sujeto + verbo) se hace referencia a un comportamiento político general, en relación positiva o negativa con la ley. Este grupo se corresponde con el tercer modelo estructural de frase ${ }^{19}$.

\section{Campos semánticos de la obediencia. Verbos con semantema de voluntad $y$ verbos sin semantema de voluntad}

Todos los verbos de obediencia hacen referencia a un rasgo de carácter o de voluntad, ya sea que éste pertenezca a su propio semantema, ya sea que lo adquiera mediante el contexto. Ello provoca que los significados verbales guarden, en gran parte, una relación semántica de equipolencia, donde cada verbo se opone a otro por un uso distintivo pro-

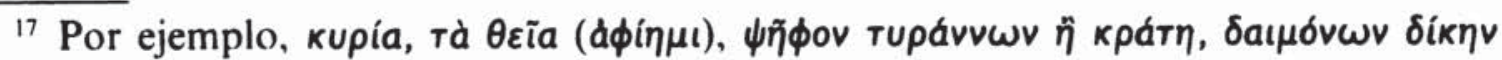

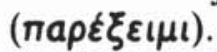

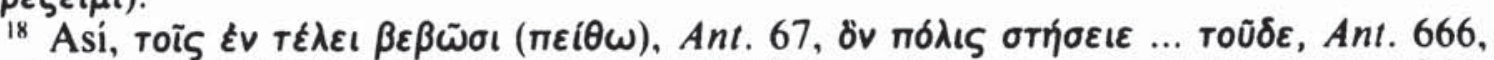

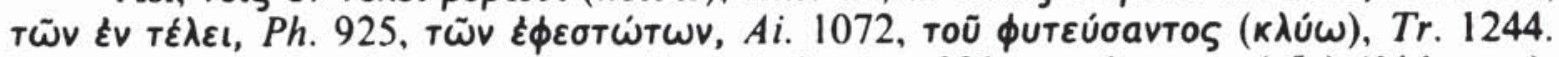

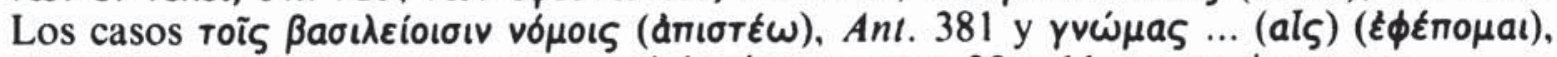
Ant. 636, responden a un uso especial: véanse notas 20 y 11 , respectivamente.

${ }_{19}$ Parece que este grupo de verbos responde en su significado a hechos de polarización. Un buen trabajo aplicado al tema de la polarización de significados lo encontramos en $\mathrm{M}$. Vílchez Díaz, "La distribución y la polarización del léxico como rasgo relevante en sociolingüística: ejemplificación sobre la Antigona de Sófocles», RSEL 17, 1987, pp. 85-94. 
pio y, a su vez, participa con cada uno de ellos en el rasgo contextual común a todos, el que indica el significado de obediencia.

Semánticamente los verbos de obediencia política son de tres tipos:

1. Verbos que llevan implícito en su significado un rasgo de carácter o voluntad, que traduce las diferentes motivaciones o causas de la obediencia. Este primer campo semántico está constituido por los ver-

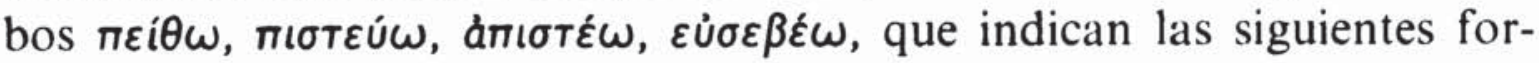
mas de obediencia: persuasión, fidelidad, infidelidad y piedad o respeto.

a) Así, contextualmente $\pi \varepsilon i \theta \omega$ traduce el significado de obedecer por persuasión y obedecer por sumisión. Es decir, indica la idea de persuasión o la idea de sumisión como forma de obediencia. El tema es el de la obediencia debida al mando político (Ant. 67).

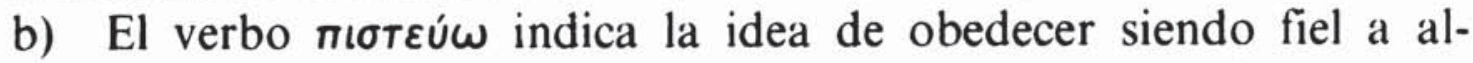
guien. El tema es el de la obediencia debida al padre ( $\operatorname{Tr}$. 1228).

c) Su contrario, ámıт́́ $\omega$, se refiere a una desobediencia por infidelidad (en este caso, a las leyes establecidas) (Ant. 219, 320,656) ${ }^{20}$, o por infidelidad como forma de carácter en el ámbito de lo político (Ant. 656).

d) Finalmente, $\varepsilon \dot{\sigma \varepsilon \varepsilon \beta \varepsilon ́ \omega}$ indica obediencia como piedad, respeto ( $\operatorname{Tr}$. 1222, El. 308), siendo los temas el de la obediencia al padre y el de la conducta del ciudadano sensato, respectivamente.

2. Verbos cuyo núcleo semántico pertenece a un campo conceptual diferente al de la obediencia, pero que pueden adquirir este valor político en usos derivados y frecuentes. Cada uno de ellos se corresponde con diferentes sustantivos de tipo abstracto que en principio nada tienen que ver con la esfera de lo moral. La única relación entre estos verbos se da cuando funcionan contextualmente con valor de verbos políti-

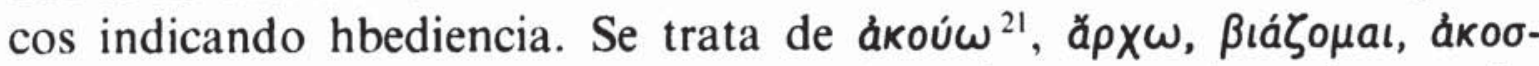
$\mu \varepsilon \dot{\omega} \omega, \kappa \lambda u ́ \omega$. En estos verbos el rasgo de carácter o voluntad procede, por lo general, del contexto próximo.

20 Aunque aquí es fácil percatarse de que el significado de desobediencia apunta más a la deslealtad de Antígona ante Creonte que ante el propio acto de transgre-

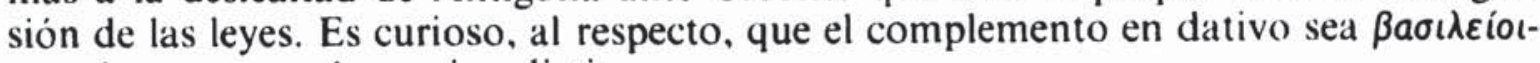

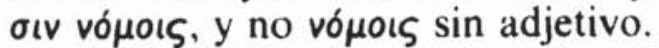

${ }_{21}$ El significado 'obedecer' no formaría parte del campo semántico 'oír', pero la proximidad secuencial ha producido en la evolución léxica de las lenguas diversas interferencias entre ellos; asi es un hecho frecuente que la expresión del contenido 'obedecer' se obtenga de 'escuchar' u 'oír', por modificación preverbial: lat. audio -

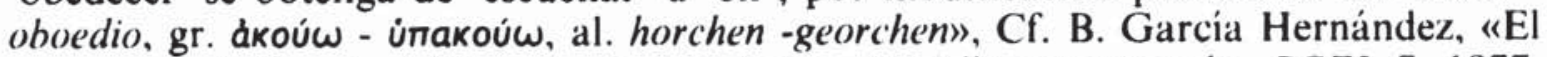
campo semántico de 'oír' en la lengua latina. Estudio estructural", RSEL 7, 1977, pp. 117-118. 
a) En ákoúw, ( $A i .591)$, el contexto próximo (los versos inmediatamente anteriores) indican que se está haciendo referencia a una obediencia como actitud de piedad. El tema es el de la piedad y el respeto en la relación del hombre con los dioses. En $O C$ 172, el contexto próximo indica la idea de obedecer por subordinación o sometimiento político. El tema es el del respeto que el ל̌́vos ha de guardar hacia las leyes de otras ciudades. En Ant. 64 se indica la idea de obedecer con una actitud de sumisión, de dependencia política. El tema es el de los deberes del polites frente al tirano.

b) El significado contextual de ă $\rho \times \omega$ añade a la idea de obediencia la idea de sumisión, acatamiento de la autoridad. El tema es el de los derechos del poder o la autoridad política como principio político incuestionable (OT. 628).

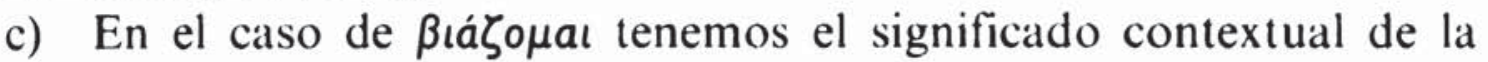
desobediencia por soberbia, rebeldía, resistencia (cf. versos inmediatamente anteriores). El sentido de rechazo con violencia va unido al de

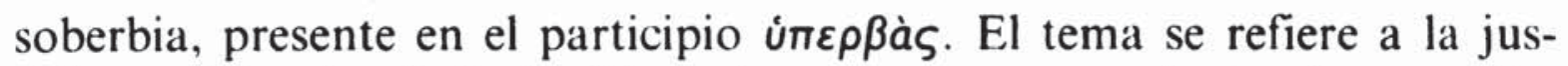
ticia en el ámbito de la familia, más concretamente, plantea la moral individual como norma de justicia política (Ant. 663). Añadamos que aquí la voz media del verbo tiene valor semántico, es decir, indica una participación especial del sujeto en la acción: se trata de una actitud de enemistad total ante las leyes, de mantener una postura de soberbia, por oposición a una postura de cumplimiento sumiso de esas leyes.

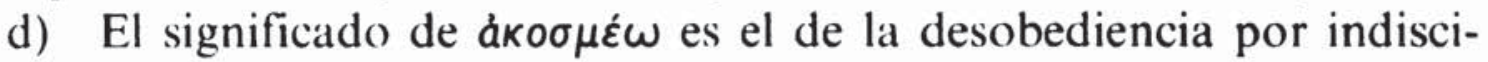
plina, y el tema es el de la actuación ilegítima en el ámbito de lo político (en un contexto más lejano el tema se concretiza en el argumento de la actitud de los Atridas y Odiseo en el certamen de las armas de Aquiles $(P h .387)$. En otro caso el valor del contexto es neutro, siendo el tema en esta ocasión el que traduce el matiz de la conducta política determinada: se trata de desobedecer la ley por incumplimiento, por negación de ésta (Ant. 720).

e) El verbo $\kappa \lambda u ́ \omega$ indica contextualmente dependencia, orden politico. El rasgo de voluntad lo aportan en esta ocasión los términos tó ěv-

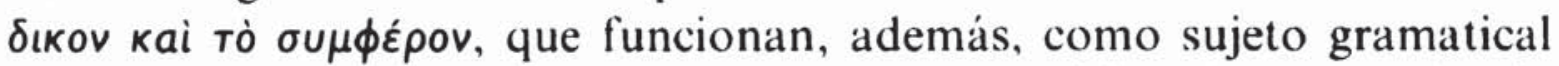
del verbo. El tema es el de la relación de la Justicia y la Conveniencia en el área de lo político $(P h .925)$. Encontramos también este mismo valor contextual pero referido al tema de la obediencia como conducta necesaria del ciudadano (noble) ante el poder en $A i$ 1352. En el siguiente uso ( $A i$. 1072) seguimos con el mismo contexto aunque con significado negativo, indicando desobediencia como independencia, negación de la ley, desacato; sin embargo, el tema cambia por una leve diferencia de 
matiz: aquí se trata de la obediencia debida al gobernante por parte del ciudadano como condición necesaria del nomos común. Vuelve a repetirse, en el significado contextual, la identificación de la idea de obediencia como disciplina, orden, acompañada de un cambio en el tema (lo separa de los anteriores igualmente una cuestión de matiz), que aquí es el de la obediencia del ciudadano al régimen tiránico (Ant. 666). El último uso del verbo indica una obediencia como actitud de reverencia y piedad: el tema es el de la obediencia debida al padre (Tr. 1244).

3. Verbos pertenecientes al campo semántico referido al movimien-

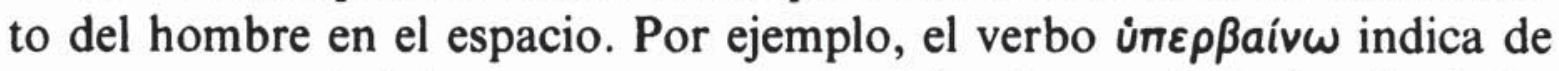
manera concreta 'atravesar, moverse en orden inverso', de donde el significado figurado de 'transgredir la ley', 'cometer delito'. Estos verbos poseen una frecuencia de uso político más retringido respecto al grupo segundo. Se trata de usos aislados y, por supuesto, figurados. Son los

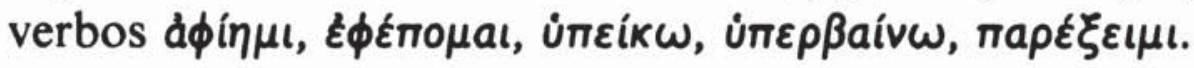

a) El primer verbo (OC 914) significa contextualmente desobedecer por causa de desprecio o irreverencia. El tema es el del ídolo patriótico, definido aquí de manera negativa (Cf. K. Reinhardt, Sófocles, Barcelona 1976, pp. 282-286). El segundo caso (OC 1537) tiene igual significado contextual que el primero. El tema es el de la soberbia política, referida concretamente al incumplimiento de las vó $\mu$ o äypaфoı. Se trata no tanto de una acción punible como de una manifestación de la voluntad política humana.

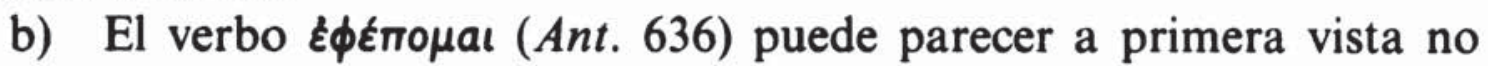
funcional políticamente, ya que puede tratarse de una lexía compuesta, es decir que verbo + complemento funcionen como un solo significado, no teniendo entonces independencia la forma verbal como significado político. Pero no es así: aunque el verbo lleva complemento de te ma político en dativo, su valor de obediencia no proviene del sintagma complemento en dativo + verbo, ya que de por sí, es decir, desprovisto de complemento, puede indicar la idea política de obediencia. El contexto nos indica obediencia por respeto y fidelidad: el tema es el de la obediencia debida al padre.

c) El verbo úncík $\omega$ indica, según el contexto próximo, fidelidad, sometimiento, acto o actitud de acatamiento; el tema es el de la obediencia a un tipo determinado de gobierno, encarnado en la figura del tirano. (OT 625).

d) Con únepßaíva podemos hablar de una coincidencia de contexto y tema: se trata de la desobediencia como rebeldía, réplica. La palabra que añade el rasgo de voluntad, no implícito en el semantema ver- 


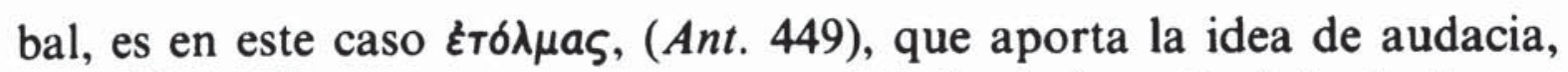
temeridad. El argumento expuesto es el de la de la actitud de Antígona ante el nomos ${ }^{22}$. En Ant. 481, la añade la forma úßpí̌દıv, indicando altanería, soberbia, y, finalmente, en Ant. 663, el rasgo de voluntad lo

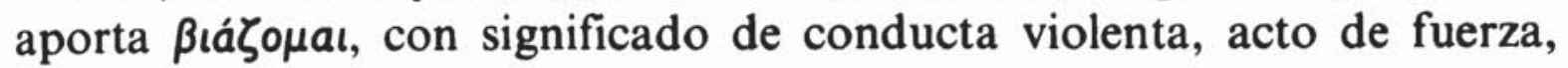
forcejeo.

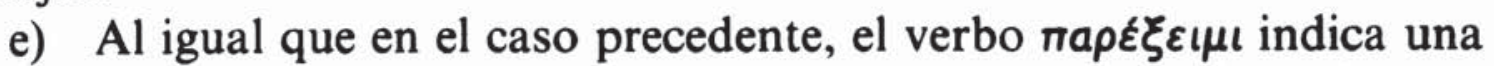
desobediencia como indocilidad, rebeldía, resistencia o réplica. El rasgo de carácter está en el sintagma vónou ßíạ. Temáticamente hace referencia al simple incumplimiento, transgresión de la ley (Ant. 60). En el segundo caso, por el contexto próximo, se interpreta la desobediencia como transgresión de la ley, delito político, siendo el tema el de la impiedad hacia los dioses, incumplimiento de las «leyes no escritas» (Ant. 921).

Estos dos últimos grupos de verbos adquieren, pues, el rasgo de carácter o voluntad a través del contexto próximo en el $90 \%$ de los casos. Se añade así al significado de obediencia (o desobediencia) política valores contextuales como sumisión, respeto, persuasión, irreverencia, desorden, traición, etc.

La diferencia entre los tres grupos de verbos radica en que, para el primer grupo, el verbo indica primariamente actitud (basada en lo que hemos llamado rasgo de voluntad), y, secundiariamente, acto; mientras que en el segundo y tercer grupo semántico, el verbo indica primariamente acto, marcándose en él la actitud o voluntad secundariamente. Por ello, en el primer grupo, el rasgo de voluntad reside en el núcleo semántico del verbo; en el segundo y tercero, la voluntad pertenece al contexto próximo, por lo general ${ }^{23}$. Consecuentemente, la situación respecto al centro del campo semántico de la obediencia, es la siguiente: los verbos del grupo primero ocupan el centro del campo, los verbos de los grupos segundo y tercero se sitúan en la periferia.

\section{Significado contextual y temas en los verbos de obediencia}

De manera general, los verbos de obediencia hacen referencia a uno de estos dos temas: la violación de la ley política $y$, por otra parte, la

${ }^{22}$ Nótese que el valor contextual sólo precisa el modus obedientiae; por contraposición el tema suele tener un protagonista concreto y conocido de los hechos, al que se añade también en otros casos un receptor de la acción. Este receptor coincide con el complemento de persona-politica.

${ }^{23} \mathrm{El}$ contexto próximo se refiere a los versos inmediatamente anteriores o posteriores al verso citado. 
piedad, según se trate de verbos de ámbito político-estatal o, en otros casos, de verbos de ámbito familiar-religioso.

Los primeros aluden al incumplimiento de la ley, bien mediante el enfrentamiento del hombre ante ésta, bien mediante el enfrentamiento del hombre ante la voluntad político-ética del tirano. Los segundos hacen referencia a temas como el de la obediencia debida al padre por parte del hijo, el de la actitud piadosa ante los dioses, el de la fidelidad o el amor entre los miembros de un mismo clan, etc.

El tema, pues, es un elemento extralingüístico de tipo circunstancial (dependiente de los argumentos que desarrolla un drama concreto). Según esto, podemos localizar la existencia de verbos-temas, comprendiendo por tales aquellos que en un drama determinado alcanzan

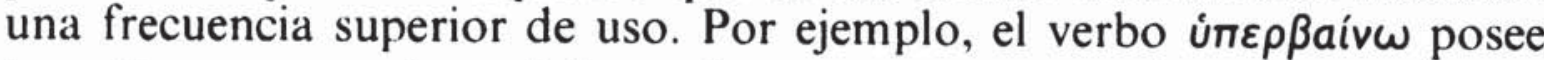
tres citas como verbo politico, y las tres pertenecen a la Antígona: existe una correspondencia, pues, entre la frecuencia de citas de un verbo en una obra y el tema que desarrolla la obra. En Antígona es obvio que el tema de la obediencia/desobediencia ocupa parte central del argumento. Otro ejemplo del verbo-tema lo tenemos en ákoúw, en el Ayax, indicando esta vez el tema de la insubordinación, traducida en una actitud de rebeldía del ciudadano respecto al poder de los superiores. Otro caso más es el de ámırर́́ $\omega$, cuyas tres citas políticas pertenecen también a la Antigona.

Independiente de este tema, cada verbo desarrolla un rasgo de voluntad o carácter, nacido del propio semantema o del contexto próximo, que no tiene por qué coincidir con aquél ${ }^{24}$. Así el verbo ámırtéw por su semantema traduce la idea de deslealtad, irreverencia, infidelidad ante la ley, pero temáticamente está aludiendo a la violación por omisión del decreto de Creonte (cf. Ant. 219).

6. Otros contextos que definen el significado en los verbos de obediencia

En cierta manera, todo son hechos contextuales cuando tratamos de definir un significado que forma parte de la cadena hablada ${ }^{25}$. Son contextuales no sólo los hechos gramaticales de distribución, sino todo lo

${ }^{24}$ Aunque en ciertas ocasiones tema y contexto se identifican. Es el caso de áoú $\omega$ en $A n t$. 64, que indica contextualmente una obediencia basada en la piedad, y el tema que desarrolla alude al respeto y piedad del hombre para con los dioses.

${ }_{25}$ Todo significado con carácter conceptual múltiple abierto a diversas interpretaciones, se define por el contexto como conjunto de condicionantes lingüisticas y extralingüísticas que afectan directamente a su sentido. 
que pueda afectar de alguna manera al significado de obediencia politica.

La tipología de contextos puede llegar a ser muy extensa, y, por otro lado, imprevisible por su condicionamiento al significado específico que se estudia. Son hechos contextuales en nuestro caso:

1) el contexto que relaciona los verbos con la idea de aspectos de la actividad humana.

2) el ámbito de referencia del verbo (verbo político o verbo familiar-religioso).

3) el significado situacional, o sea, el valor cultural o social del concepto de obediencia en Sófocles.

4) la doble perspectiva a la que responde el tema de la obediencia en Sófocles: por una parte, la obediencia como factor imprescindible del orden político ( $\kappa \lambda u ́ \omega, A i$. 1352), por otra, la obediencia como imposición de la voluntad desmedida del tirano, es decir, la obediencia política como aberración humana.

5) el contexto próximo y el contexto lejano, referente a los versos inmediatamente anteriores o posteriores al verbo de obediencia, o referente a cualquier pasaje distante del verbo en cuestión, pero que incide directamente en su interpretación. Ocurre, por ejemplo, con el verbo $\varepsilon \dot{\sigma} \sigma \varepsilon \beta \varepsilon \dot{c} \omega$, que se encuentra rodeado de verbos que indican obe-

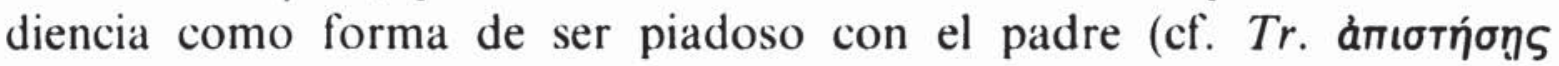

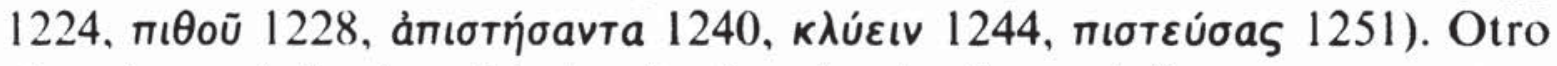
ejemplo es el de $A n t ., 64$, donde el verbo ákoúw se define por su contra-

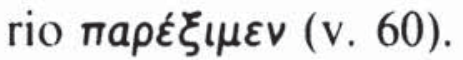

6) el contexto producto de la polarización de los significados. Esta polarización se manifiesta de dos maneras: a) polarización por la que se define un significado en relación con la «intencionalidad» del personaje que lo emite ${ }^{26}, y$ b) polarización definida como suposición o explicitación contextual, característica del tercer grupo de verbos (intransitivos sin ningún tipo de complemento). En este caso, el significado resultante no tiene por qué oponerse necesariamente a otro significado, supuesto o real, de un personaje contrario o rival del que emite el mensaje. Es el caso de Ai. 591: el participio ákoúovoiv se refiere a los que deben obedecer a los dioses, es decir, a los que deben practicar una conducta de piedad con los dioses. El primer caso se extiende teóricamente al conjunto

26 Adrados lo comprende como parte de lo que llama "contexto lejano", tiene que ver con la "interpretación" que hace el personaje de los significados que emite el receptor. Cf., "La lexicografia griega: su estado actual y el Diccionario Griego-Español», Nuevos estudios de Lingüistica general y de teoria literaria. Barcelona 1988. p. 191. 
de los verbos de obediencia: dado que éstos indican acto unido a una conducta moral, o, lo que es lo mismo, una actuación valorada éticamente, esa conducta moral se puede interpretar como opuesta según el personaje que la refiera. Así, para Creonte, 'obrar piadosamente' ( $\varepsilon \dot{\sigma} \sigma \varepsilon-$ $\beta \varepsilon \hat{\varepsilon} \omega)$ se refiere a obrar respetando las leyes establecidas para la ciudad; mientras que Antígona, utilizando el mismo verbo, hará referencia a los que obran respetando los lazos de sangre en la comunidad familiar.

7) el que llamamos contexto referencial interno ${ }^{27}$. Un ejemplo de éste lo podemos hallar en el verbo $\varepsilon \dot{\phi} \dot{n}$.

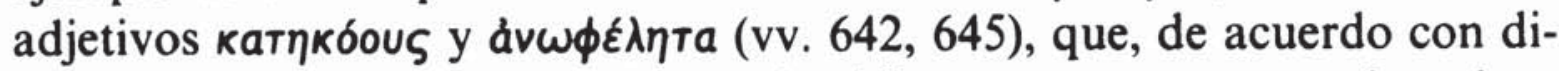
cho contexto, debemos referirlos a los hijos que se someten a la voluntad del padre, y los que no son obedientes o sumisos y toman un camino ético desviado del paterno, respectivamente.

8) la doble valoración - positiva o negativa - que conllevan ciertos términos (véase en la traducción que damos en el apéndice, el caso de $\pi \varepsilon i \theta \omega$ en Ant. 67).

A estos hechos podemos añadir, de manera teórica, la posible existencia de fenómenos de ambigüedad, usos especiales de ciertos términos, usos figurados o literarios (es decir, estilísticos), contextos subjetivos, peyorativos o positivos ${ }^{28} \ldots$

Pero sucede que también los hechos sintácticos, gramaticales o distribucionales influyen directamente en los significados, modificándolos en varios aspectos, según las siguientes pautas:

1) las relaciones funcionales del verbo con el resto de la frase (rec-

${ }^{27}$ Este contexto traduce los rasgos peculiares de tipos determinados de realia 0 referentes. En nuestro caso concreto recubre la siguiente consideración: por una parte, se equipara con lo que Coseriu llama "universo de discurso"; "Sistema universal de significaciones al que pertenece un discurso - o enunciado - y que determina su validez y su sentido", cf. E. Coseriu, "Determinación y entorno. Dos problemas de una lingüística del hablar", $R J b 7,1955-56$, p. 49. Por otra, se puede identificar - como parte integrada en este universo de discurso-, con lo que Martínez Hernández llama «contexto mitológico»: «... Además del contexto lingüístico, en nuestro campo nominal del dolor en Sófocles hemos recurrido muchas veces a un tipo de contexto extralingüístico que denominamos contexto mitológico. Esto quiere decir que determinamos el tipo de dolor que un lexema expresa en un contexto determinado por la referencia al personaje al que alude», cf. "El campo léxico de los sustantivos de dolor en Sófocles. Ensayo de Semántica estructural funcional», CFC 13, 1977, pp. 52-53.

28 Adrados aún añade otros, como, por ejemplo, contexto temporal/atemporal, contexto que opone la vida humana a otros niveles, contexto de dirección y movimiento, etc., en estrecha dependencia con las características propias del campo semántico de que se trate: cada frase o unidad significativa se apoyará en contextos condicionados exclusivamente por su naturaleza real e intelectual. Cf. «Organización de los artículos del Diccionario..." (v. supra). 
ción del verbo, construcción con diversos tipos de complementos), que origina una división en dos grandes subclases: transitivos e intransitivos.

2) la clase (tipo semántico) de verbo, es decir, verbo que indica voluntad en su semantema, verbo que no indica carácter o voluntad en su semantema, etc.

3) las subclases de palabras que definen el significado funcionalmente desde una perspectiva gramatical. En nuestro caso serían sujeto activo y de persona, sujeto de persona-política, complemento de tema-tipo y complemento de persona politica.

4) las diversas oposiciones que definen a un verbo frente a su contrario.

5) las neutralizaciones de ciertas oposiciones, y, en general, cualquier tipo de condicionante semántico relacionado con hechos gramaticales o sintácticos, que una o desligue al verbo de obediencia de otro u otros verbos, precisando su valor semántico ante el receptor del mensaje.

\section{Apéndice $^{29}$}

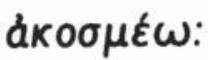

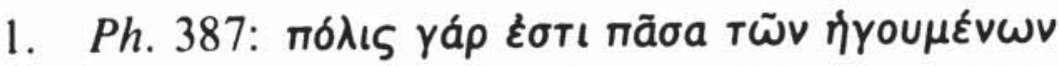

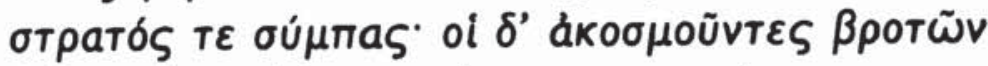

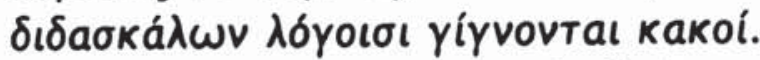

[Neoptólemo a Filoctetes] Porque la ciudad y el ejército entero son de los que mandan, y quienes de los mortales obran contra la ley se han hecho perturbadores por los consejos recibidos de sus maestros.

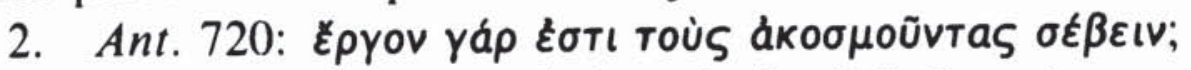

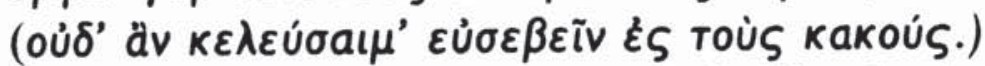

[Creonte pregunta a su hijo Hemón] - ¿Estás hablando de dar honra a los que han desobedecido la ley?, - (No te exhortaría yo a respetar a los malhechores).

${ }^{29}$ Damos en el Apéndice las citas del griego, así como su traducción al español, con el objeto de que se haga más cómoda la lectura del trabajo mediante la consulta de los textos. 
ákoúw

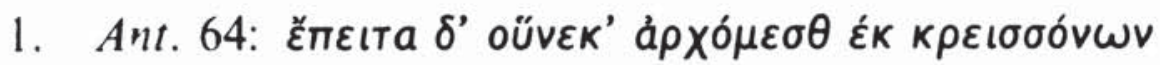

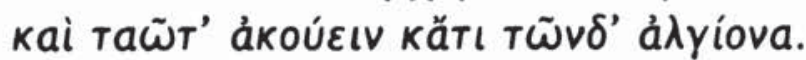

[Ismene a Antígona refiriéndose al decreto de Creonte] ... Y, después, que nos mandan los que tienen más poder, por ello tenemos que obedecer en esto y aun en cosas más dolorosas que éstas.

\section{ảmıTŕ́}

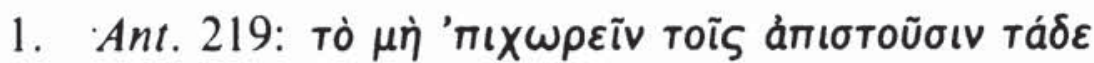

[Creonte dirigiéndose al Coro] ... que no tengáis piedad con los que no sean fieles a esta orden.

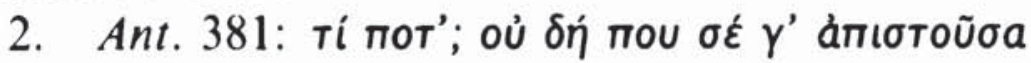

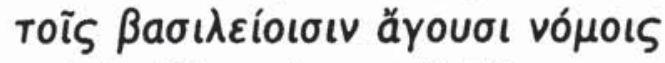

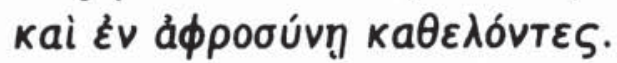

[El Coro pregunta a Antigona] ¿Qué ocurre? ¿Acaso te traen detenida por haber desobedecido las leyes de Creonte, por haberte sorprendido en un acto de locura?

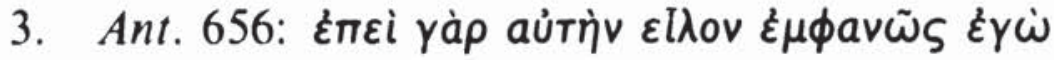

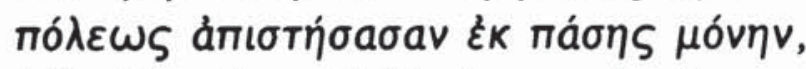

[Creonte a su hijo Hemón refiriéndose a Antígona]: De toda la ciudad sólo a ella he sorprendido abiertamente en actitud de desobediencia.

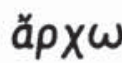

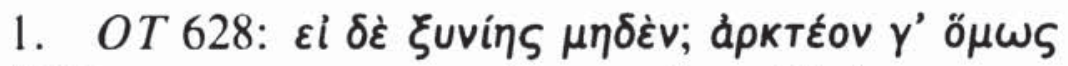

[Edipo en respuesta a Creonte] - ¿Y si no comprendes nada? - A pesar de todo hay que obedecer.

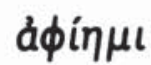

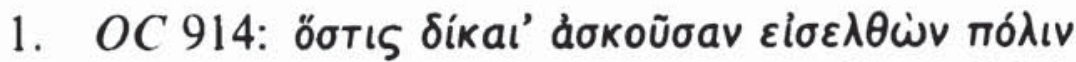

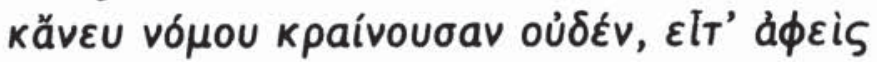

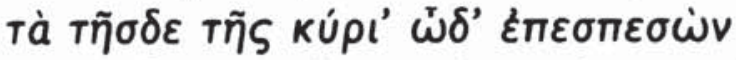

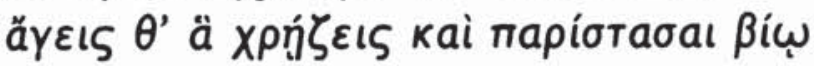

[Teseo a Creonte] Has cometido acciones indignas de mi, de aquellos de los que tú mismo has nacido y de tu país, porque, entrando en una ciudad que observa la justicia, que nada realiza que esté fuera de la ley, y despreciando las sagradas leyes de esta tierra, irrumpes así en ella, te llevas lo que quieres y lo pones a tu lado por la fuerza. 
2. OC 1537: ai $\delta \dot{\varepsilon} \mu u p i a ı$ nódeıs,

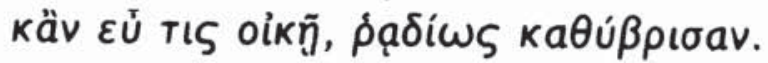

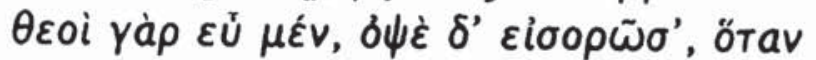

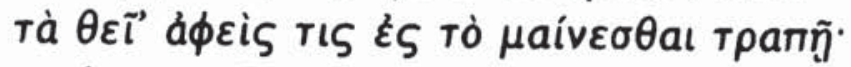

[Edipo conversando con Teseo] Innumerables ciudades, aunque uno las gobierne bien, caen en la insolencia con facilidad, pero los dioses se dan buena cuenta, a pesar de que pase el tiempo, de cuando alguien se vuelve hacia la locura despreciando las normas divinas.

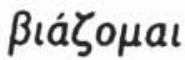

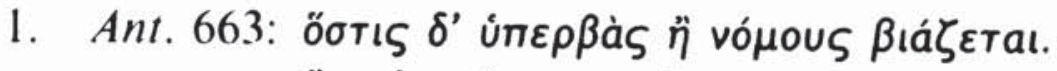

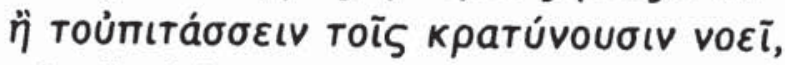

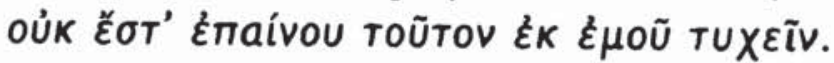

[Creonte a su hijo Hemón] El que con los asuntos de la casa es persona diligente, también se mostrará justo con la ciudad. Pero quien quebranta o fuerza las leyes o pretende imponerse a los que mandan, no es posible que obtenga mi elogio.

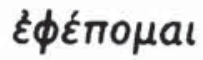

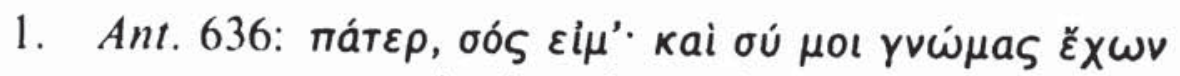

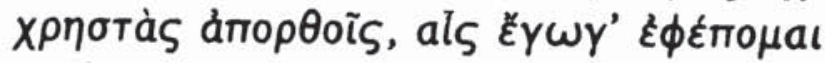

[Hemón a su padre Creonte]: Padre, tuyo soy, y tú derechamente me encaminas con tus beneficiosos consejos, que siempre he de seguir.

$$
\varepsilon \dot{\sigma} \sigma \varepsilon \beta \varepsilon \dot{\varepsilon} \omega
$$

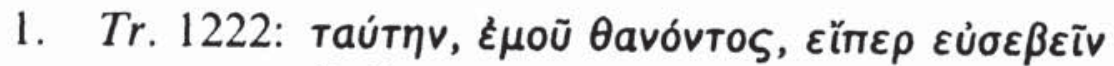

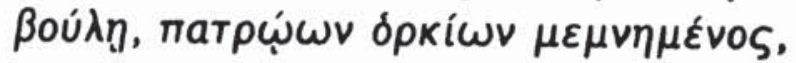

[Heracles a su hijo Hilo] (Te encomiendo lo siguiente, hijo): cuando yo muera, si quieres obrar piadosamente y recordar los juramentos paternos, (tómala por esposa)...

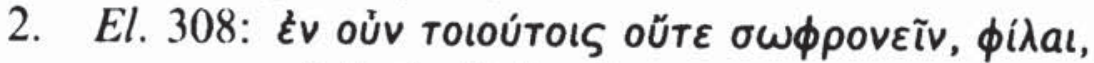

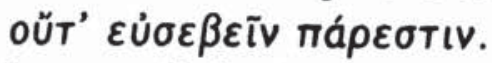

[Electra al Coro refiriéndose a sí misma] En semejante situación, amigas, no es posible ser sensata ni piadosa.

\section{$\kappa \lambda u ́ \omega$}

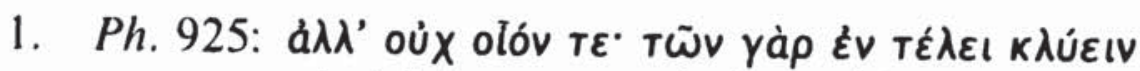

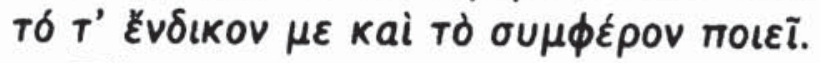

[Neoptólemo a Filoctetes] (Devuélveme mi arco) - No es posible, 
la justicia y la conveniencia me obligan a obedecer a los que están en el poder.

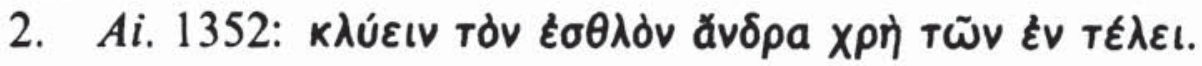

[Agamenón a Odiseo] Es preciso que el hombre noble obedezca a los que tienen el poder.

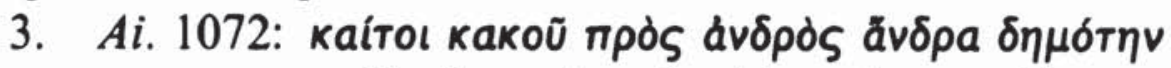

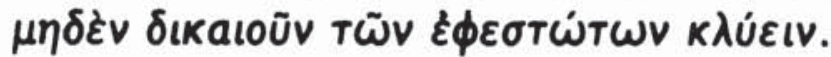

[Menelao a Teucro acerca de Ayax]: $Y$ en verdad que es propio de un traidor el negarse un hombre del ejército a desobedecer por norma a sus superiores.

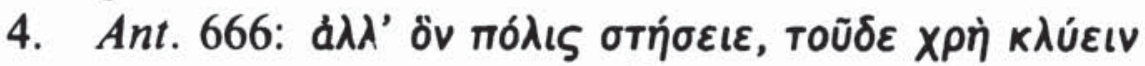

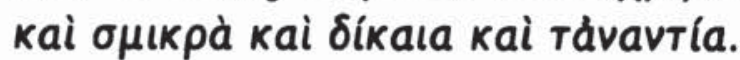

[Creonte hablando a su hijo Hemón] Aquel que la ciudad ha instituido como jefe, a ése hay que obedecer, en lo insignificante, en lo que es justo e incluso en lo que no lo es.

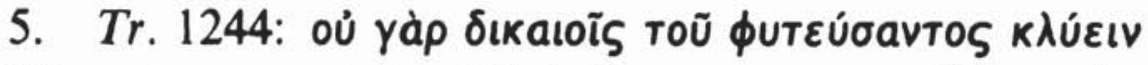

[Heracles a su hijo Hilo] Porque no consideras justo obedecer al que te engendró.

\section{$\pi a \rho \varepsilon \xi \xi \iota \iota$}

1. Ant. 60:

$$
\varepsilon l \text { vónou } \beta i ́ \omega
$$

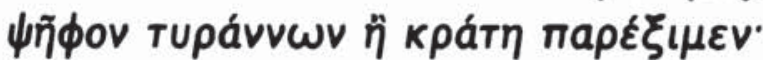

[Ismene a su hermana Antígona] ( $\mathrm{Y}$ ahora piensa con cuánto mayor infortunio pereceremos nosotras dos, solas como hemos quedado, si), oponiéndonos a la ley, transgredimos el decreto o el poder del tirano.

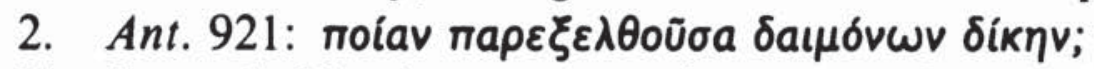

[Antígona hablando consigo misma ante Creonte] ¿Por haber transgredido una ley divina? ¿Cuál?

$$
\pi \varepsilon i \theta \omega
$$

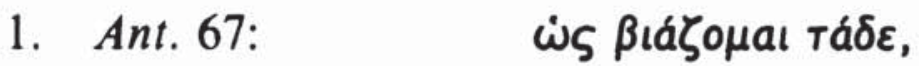

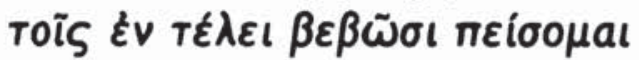

[Ismene] Y yo, porque a ello me veo obligada, obedeceré sumisa a los que tienen el poder.

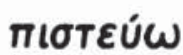

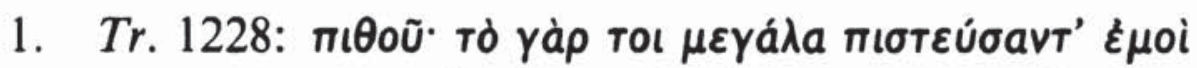

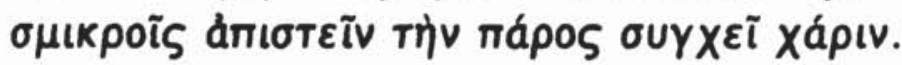

[Heracles a su hijo Hilo]: Obedece, ya que me has seguido en las 
grandes cosas, el no seguirme en las pequeñas inutiliza el agradecimiento anterior.

\section{ن்ríkw}

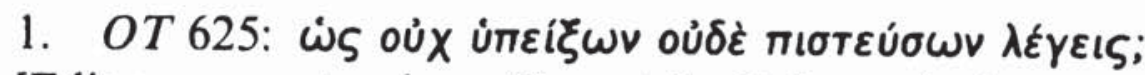

[Edipo preguntando a Creonte] ¿Quieres decir que no me obedecerás ni me darás crédito?

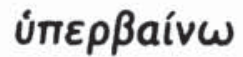

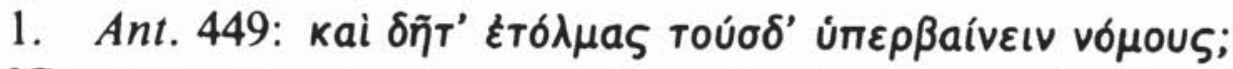

[Creonte preguntando a Antígona] Y, a pesar de ello, ¿te atreviste a transgredir estos decretos?

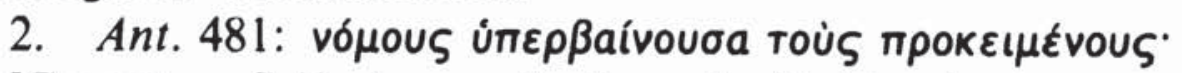

[Creonte refiriéndose a Antígona] ..Habiendo transgredido las leyes establecidas.

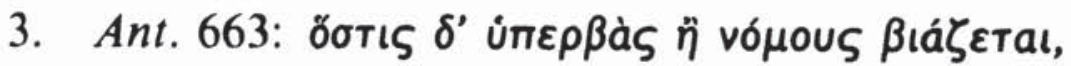

[Creonte habla a Hemón refiriéndose a Antígona]. Y quien, soberbio, se opone a las leyes con violencia...

Antonia Carmona Vázquez 